\title{
Antimicrobial Activity and Cytotoxicity of Bis(indole) Alkaloids from the Sponge Spongosorites sp.
}

\author{
Ki-Bong OH, ${ }^{*, a, b}$ Woongchon Mar, ${ }^{c}$ Sanghee KIM ${ }^{c}$ Ji-Yun KIm, ${ }^{c}$ Tae-Hoon LeE, ${ }^{a}$ Jae-Gyu KIm, ${ }^{a, b}$ \\ Daehyun ShIN, ${ }^{c}$ Chung J. Sim, ${ }^{d}$ and Jongheon SHIN ${ }^{*, c}$ \\ ${ }^{a}$ Seoul National University, School of Agricultural Biotechnology; Seoul 151-921, Korea: ${ }^{b}$ Center for Agricultural \\ Biomaterials, Seoul National University; Seoul 151-921, Korea: ' Natural Products Research Institute, College of \\ Pharmacy, Seoul National University; Seoul 110-460, Korea: and ${ }^{d}$ Department of Biology, Hannam University; Taejeon \\ 300-791, Korea. Received September 26, 2005; accepted November 17, 2005
}

Bis(indole) alkaloids, of the topsentin class (1-4) and hamacanthin class (5-9), isolated from the marine sponge Spongosorites sp. were investigated using several biological assays. In the evaluation of antimicrobial activity against various strains of bacteria and fungi, compounds of the hamacanthin class exhibited more potent antibacterial activity than those of the topsentin class. Deoxytopsentin (1) and hamacanthin A (5) also exhibited significant antibacterial activity against methicillin-resistant Staphylococcus aureus, with MIC values of less than $12.5 \mu \mathrm{g} / \mathrm{ml}$. In the antifungal activity test, hamacanthins, especially hamacanthin A (5), showed potent inhibitory activity against medically important pathogenic fungi. In contrast, all of the topsentins (1-4) were inactive against fungal growth. These compounds (1-9) also exhibited moderate cytotoxicity against cancer cell lines at concentrations between 1.1 and $>20 \mu \mathrm{g} / \mathrm{ml}$.

Key words Spongosorites sp.; topsentin; hamacanthin; antimicrobial activity; cytotoxicity

The increasing occurrence of infectious diseases is becoming a worldwide problem. Additionally, the resistance problem demands that renewed efforts be made to seek antimicrobial agents that are effective against pathogenic microorganisms resistant to current treatment. ${ }^{1)}$ Many compounds have been developed from terrestrial sources, especially from plants and microorganisms including actinomycetes and fungi. However, the number of reports of novel compounds from terrestrial sources has been decreasing rapidly. Marine organisms are an outstanding source of unusual, biologically active natural products, which may be considered as potential new drug leads useful for the treatment of human diseases. $^{2-4)}$

Indole-containing alkaloids have frequently been isolated from diverse marine invertebrates including bryozoans, coelenterates, sponges, and tunicates. Over the past few years, much attention has been paid to the search for specific bis(indole) secondary metabolites due to their novel structural features and broad spectrum of powerful biological activities. ${ }^{5)}$ Bis(indole) alkaloids, consisting of two indole moieties connected to each other via heterocyclic units, are particularly abundant in sponges. Since topsentin, a bis(indolyl)imidazole, and its analogues were isolated from the sponge Topsentia genitrix (=Spongosorites genitrix), ${ }^{6}$ metabolites containing the bis(indole) moiety have been found with various carbon skeletons and functionalities. ${ }^{7-13)}$ These compounds exhibit a wide spectrum of pharmacologic activities such as cytotoxic, ${ }^{10-12,14)}$ antitumor, ${ }^{13)}$ antiviral, ${ }^{13)}$ antimicrobial, ${ }^{8,11,14)}$ and antiinflammatory activities as well as binding to the $\alpha 1$-adrenergic receptor ${ }^{15)}$ that make bis(indole) alkaloids attractive targets for biomedical and synthetic studies.

During the course of our search for inhibitors of sortase A (SrtA), a bacterial surface protein anchoring transpeptidase which plays key roles in cell-wall protein anchoring and virulence in Gram-positive bacteria, from marine organisms, we encountered the bright yellow sponge Spongosorites sp. (Order Halichondrida, Family Halichondriidae) of which the crude extract exhibits significant inhibitory activity against SrtA. A subsequent chemical investigation of the Spongosorites sp. crude extract led to the isolation and structural determination of nine indole-containing alkaloids. ${ }^{16)}$ However, a more in-depth investigation of their biological properties appears desirable. Here, we report a wider biological evaluation of the antimicrobial activity of bis(indole) alkaloids against various bacteria and fungi, as well as their cytotoxicities against several cancer cell lines.

\section{MATERIALS AND METHODS}

General Bis(indole) alkaloids (Fig. 1), topsentin class (1-4) and hamacanthin class (5-9), were obtained during a previous study. ${ }^{16)}$ Samples were stored in a freezer at $-80^{\circ} \mathrm{C}$ until needed. All other reagents used were of the highest grade available from commercial sources. Sixteen strains of microorganisms were used for antimicrobial activity tests (Tables 1, 2): three Gram-negative bacteria (Escherichia coli ATCC 35218, Proteus vulgaris ATCC 3851, and Salmonella typhimurium ATCC 14028); eight Gram-positive bacteria (Bacillus subtilis ATCC 6633, Micrococcus leuteus IFO 12708, and Staphylococcus aureus (ATCC 6538p, 13709, 29213) including methicillin-resistant (MRSA) strains (ATCC 43300, 700787, 700788)); five fungi (Candida albicans ATCC 10231, C. albicans IFO 1594, Trichophyton rubrum IFO 9185, Trichophyton mentagrophytes IFO 40996, and Aspergillus fumigatus HIC 6094). AGS (human gastric adenocarcinoma), L1210 (mouse lymphocytic leukemia), BC (human breast cancer), and HepG2 (hepatoma) cancer cell lines were purchased from the American Type Culture Collection (Rockville, MD, U.S.A.) and cultured in RPMI 1640.

In Vitro Antibacterial Activity The effects of bis(indole) alkaloids on bacterial growth were determined using the 96-well microtiter broth dilution method. ${ }^{17)}$ Briefly, bacteria were grown overnight in Standard Methods Broth (SMB) (Difco), harvested by centrifugation, and then washed 
twice with sterile distilled water. Stock solutions of bis(indole) alkaloids were prepared in dimethyl sulfoxide and stored at $-20^{\circ} \mathrm{C}$. Each stock solution was diluted with SMB to prepare serial two-fold dilutions in the range of 100 to $0.05 \mu \mathrm{g} / \mathrm{ml}$. One hundred microliters of the broth containing about $10^{5}$ colony-forming units (cfu) $/ \mathrm{ml}$ of test bacteria was added to each well of a 96-well microtiter plate. Culture plates were incubated for $24 \mathrm{~h}$ at $37^{\circ} \mathrm{C}$, and optical density at $600 \mathrm{~nm}\left(\mathrm{OD}_{600}\right)$ was measured using a Multiskan Spectrum spectrophotometer (Thermo Labsystems Inc., Beverly, MA, U.S.A.). The minimum inhibitory concentration (MIC) values were the lowest concentration of test compounds that inhibited cell growth. Ampicillin and oxacillin were used as reference compounds.

In Vitro Antifungal Activity The antifungal activities of bis(indole) alkaloids against Candida spp. were determined by following broth dilution method M27-A2, which was proposed by the US National Committee for Clinical Laboratory Standards. ${ }^{18,19)}$ Each stock solution of bis(indole) alkaloids was diluted with RPMI 1640 broth (MOPS $0.165 \mathrm{~m}$ buffer at $\mathrm{pH}$ 7.0) (Sigma-Aldrich) to prepare serial two-fold dilutions in the range of 100 to $0.05 \mu \mathrm{g} / \mathrm{ml}$. One hundred microliters of the broth containing about $10^{3}$ cells $/ \mathrm{ml}$ was added to each well of a 96-well microtiter plate, and the MIC was determined after $2-\mathrm{d}$ incubation at $28^{\circ} \mathrm{C}$. The antifungal spectra against filamentous fungi were determined using the broth dilution method of the Association of Official Analytical Chemists. $^{20)}$ A spore suspension was collected with a $0.1 \%$ Tween-80 solution from potato dextrose agar (PDA, Difco) plates that had been incubated at $28^{\circ} \mathrm{C}$ for 2 weeks. Spores were washed three times with sterile distilled water and resuspended in distilled water to obtain an initial inoculum size of $10^{5} \mathrm{spores} / \mathrm{ml}$. Sabouraud glucose broth $(2.0 \%$ glucose, $1.0 \%$ neopeptone) (Difco) was used as the antifungal activity test medium. Amphotericin B was used as a reference compound. The MIC was defined as the lowest concentration of compound at which no growth was observable after being incubated for $4 \mathrm{~d}$ at $28^{\circ} \mathrm{C}$.

Cytotoxicity Test The cytotoxicity of bis(indole) alkaloids against AGS, L1210, BC, and HepG2 cancer cell lines was determined using the MTT method. ${ }^{21)}$ Briefly, adherent cancer cell lines (AGS, BC, and HepG2) at the concentration of $0.3 \times 10^{5}$ cells $/ \mathrm{ml}$ and suspended cells (L1210) at $0.5 \times 10^{5}$ cells $/ \mathrm{ml}$ were seeded in 96-well microplates. The adherent cells were incubated for $18 \mathrm{~h}$ to allow cell attachment. The alkaloid solutions were added to the cell cultures at concentrations of $0.31-20 \mu \mathrm{g} / \mathrm{ml}$, and the cells were incubated for $24 \mathrm{~h}$. The MTT solution was added $3 \mathrm{~h}$ before the end of the incubation. Cell survival was evaluated with a multiwell scanning spectrophotometer at $540 \mathrm{~nm}$.

\section{RESULTS AND DISCUSSION}

Bis(indole) alkaloids are recognized as one of the rapidly growing groups of sponge metabolites. ${ }^{14)}$ In a previous study, ${ }^{16)}$ a new bis(indole) alkaloid (9) of the hamacanthin class along with previously reported compounds of the related structural classes, the topsentin class (1-4) and hamacanthin class $(\mathbf{5}-\mathbf{8})$, were isolated from the marine sponge Spongosorites sp. (Fig. 1). Compounds $\mathbf{1 - 9}$ were identified as deoxytopsentin (1), ${ }^{6}$ bromodeoxytopsentin (2), ${ }^{7,12)}$ bromotopsentin (3), ${ }^{6}$ 4,5-dihydro-6"-deoxybromotopsentin (4), ${ }^{6}$ hamacanthin A (5), ${ }^{8)}$ trans-4,5-dihydrohamacanthin $\mathrm{A}(\mathbf{6}),{ }^{7}$ hamacanthin $\mathrm{B}(7),{ }^{8)}$ 6"-debromohamacanthin $\mathrm{A}(\mathbf{8}),{ }^{14)}$ and $66^{\prime \prime}$-debromohamacanthin B (9). ${ }^{16)}$

The antibacterial activities of the nine isolated compounds against Gram-negative and Gram-positive bacteria including MRSA are summarized in Table 1. Among the topsentins (1-4), deoxytopsentin (1) showed the most potent antibacterial activity against various bacteria including MRSA

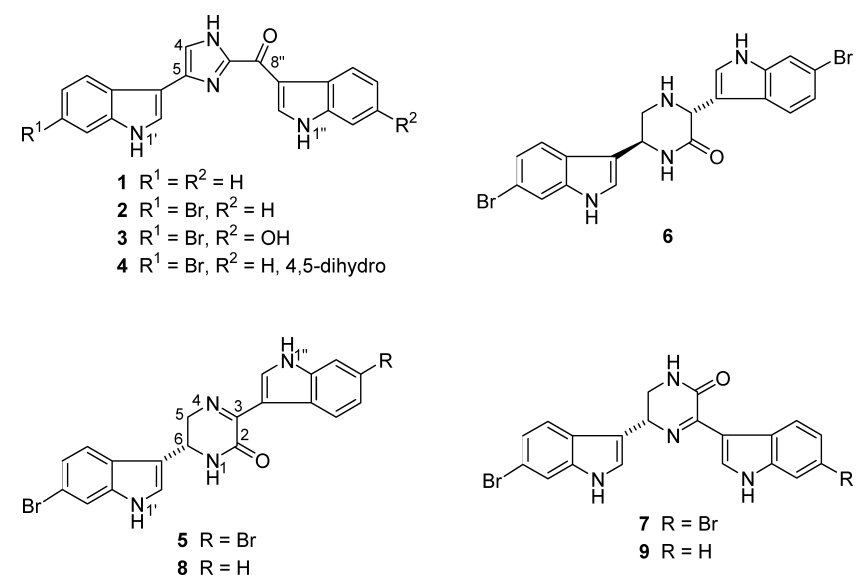

Fig. 1. Chemical Structures of Bis(indole) Alkaloids from the Sponge Spongosorites sp.

Table 1. In Vitro Antibacterial Activity of Compounds $\mathbf{1}-\mathbf{9}$ against Gram-Positive and Gram-Negative Bacteria

\begin{tabular}{|c|c|c|c|c|c|c|c|c|c|c|c|}
\hline \multirow{2}{*}{ Organisms } & \multicolumn{10}{|c|}{$\operatorname{MIC}(\mu \mathrm{g} / \mathrm{ml})$} & \multirow[b]{2}{*}{ OX } \\
\hline & 1 & 2 & 3 & 4 & 5 & 6 & 7 & 8 & 9 & $\mathrm{AM}$ & \\
\hline B. subtilis ATCC 6633 & 6.25 & 12.5 & 12.5 & 100 & 1.56 & 6.25 & 6.25 & 6.25 & 50 & 12.5 & 1.56 \\
\hline M. leuteus IFO 12708 & 6.25 & 50 & 12.5 & $>100$ & 1.56 & 6.25 & 3.12 & 6.25 & 50 & 0.05 & 0.05 \\
\hline S. aureus ATCC 6538p & 3.12 & 50 & 25 & $>100$ & 3.12 & 12.5 & 6.25 & 6.25 & 50 & 0.78 & 0.39 \\
\hline S. aureus ATCC 13709 & 3.12 & 50 & 12.5 & $>100$ & 3.12 & 12.5 & 3.12 & 6.25 & 50 & 0.78 & 0.39 \\
\hline S. aureus ATCC 29213 & 12.5 & 50 & 25 & $>100$ & 3.12 & 12.5 & 6.25 & 6.25 & 50 & 0.78 & 0.39 \\
\hline MRSA ATCC 43300 & 12.5 & 100 & 25 & $>100$ & 3.12 & 12.5 & 6.25 & 6.25 & 50 & 6.25 & 12.5 \\
\hline MRSA ATCC 700787 & 12.5 & 50 & 25 & $>100$ & 3.12 & 25 & 3.12 & 12.5 & 50 & 3.12 & 50 \\
\hline MRSA ATCC 700788 & 6.25 & 50 & 25 & $>100$ & 3.12 & 25 & 6.25 & 12.5 & 50 & 6.25 & 12.5 \\
\hline E. coli ATCC 35218 & $>100$ & $>100$ & $>100$ & $>100$ & $>100$ & $>100$ & $>100$ & $>100$ & $>100$ & 3.12 & 0.78 \\
\hline P. vulgaris ATCC 3851 & 6.25 & 25 & 25 & $>100$ & 0.78 & 12.5 & 3.12 & 3.12 & 50 & 6.25 & 1.56 \\
\hline S. typhimurium ATCC 14028 & 12.5 & 100 & 50 & $>100$ & 3.12 & 25 & 6.25 & 12.5 & 100 & 12.5 & 3.12 \\
\hline
\end{tabular}

MRSA $=$ methicillin-resistant Staphylococcus aureus; $\mathrm{AM}=$ ampicillin; $\mathrm{OX}=$ oxacillin 
Table 2. In Vitro Antifungal Activity of Compounds $\mathbf{1}-\mathbf{9}$

\begin{tabular}{|c|c|c|c|c|c|c|c|c|c|c|}
\hline \multirow{2}{*}{ Organisms } & \multicolumn{10}{|c|}{$\mathrm{MIC}(\mu \mathrm{g} / \mathrm{ml})$} \\
\hline & 1 & 2 & 3 & 4 & 5 & 6 & 7 & 8 & 9 & Amphotericin B \\
\hline C. albicans ATCC 10231 & $>100$ & $>100$ & $>100$ & $>100$ & 6.25 & 50 & 25 & 50 & $>100$ & 0.10 \\
\hline C. albicans IFO 1594 & $>100$ & $>100$ & $>100$ & $>100$ & 6.25 & 50 & 100 & 50 & $>100$ & 0.10 \\
\hline T. rubrum IFO 9185 & 100 & $>100$ & $>100$ & $>100$ & 25 & 50 & $>100$ & 50 & $>100$ & 3.12 \\
\hline T. mentagrophytes IFO 40996 & $>100$ & $>100$ & $>100$ & $>100$ & 12.5 & 25 & 50 & 25 & $>100$ & 3.12 \\
\hline A. fumigatus HIC 6094 & $>100$ & $>100$ & $>100$ & $>100$ & 50 & 100 & $>100$ & 100 & $>100$ & 12.5 \\
\hline
\end{tabular}

Table 3. Cytotoxicity of Compounds $\mathbf{1}-\mathbf{9}$ against Cancer Cell-Lines

\begin{tabular}{|c|c|c|c|c|c|c|c|c|c|}
\hline \multirow{2}{*}{ Cell-lines } & \multicolumn{9}{|c|}{$\mathrm{IC}_{50}(\mu \mathrm{g} / \mathrm{ml})$} \\
\hline & 1 & 2 & 3 & 4 & 5 & 6 & 7 & 8 & 9 \\
\hline AGS & 1.3 & 3.3 & 1.4 & 6.3 & 3.9 & 6.3 & 5.1 & 7.5 & 7.5 \\
\hline L1210 & 7.4 & 1.1 & 6.9 & 5.1 & 3.0 & 5.3 & 6.7 & 9.0 & 7.7 \\
\hline $\mathrm{BC}$ & 10.7 & $>20$ & $>20$ & 17.5 & 12.5 & $>20$ & $>20$ & $>20$ & $>20$ \\
\hline HepG2 & 3.3 & $>20$ & $>20$ & $>20$ & 12.5 & $>20$ & $>20$ & $>20$ & $>20$ \\
\hline
\end{tabular}

AGS: human gastric adenocarcinoma; L1210: mouse lymphocytic leukemia; BC: human breast cancer; HepG2: hepatoma.

(MIC: $3.12-12.5 \mu \mathrm{g} / \mathrm{ml}$ ). Interestingly, insertion of a bromine atom at the C- $6^{\prime}$ position (compound 2) resulted in a dramatic decrease in the inhibitory activity (MIC: 12.5$100 \mu \mathrm{g} / \mathrm{ml})$ on bacterial cell growth. In addition, the 4,5-dihydrogenation of the imidazole ring (compound 4) led to a total loss of activity ( $\geq 100 \mu \mathrm{g} / \mathrm{ml}$ ) against bacterial growth at the highest concentration tested. These results suggest that the antibacterial activity of topsentins are greatly affected by the substitution on the indole and imidazole rings. Bis(indole) compounds of the hamacanthin class (5-9) also exhibited significant antibacterial activity. Hamacanthin A (5) showed the most potent antibacterial activity (MIC: 0.78 $3.12 \mu \mathrm{g} / \mathrm{ml}$ ), in particular against MRSA (MIC: $3.12 \mu \mathrm{g} / \mathrm{ml}$ ), among the hamacanthins, and the MIC values obtained for this compound were comparable to those obtained for ampicillin (MIC: $3.12-6.25 \mu \mathrm{g} / \mathrm{ml}$ ) and oxacillin (MIC: $12.5-$ $50 \mu \mathrm{g} / \mathrm{ml}$ ). The antibacterial activity of compound 6 (trans3,4-dihydrohamacanthin A) was 4-16-fold less than that of compound 5. In addition, compound 5, with a 3,6-disubstituted pyrazinone ring, was significantly more active than compound 7, with the corresponding 3,5-disubstituted pyrazinone ring. These results indicate that the antibacterial activity of hamacanthins is attributable to the 3,6-disubstituted-5,6-dihydro-1(2H)-pyrazinone skeleton. However, all of the compounds tested, both topsentins and hamacanthins, were inactive against $E$. coli.

Antifungal activity was evaluated against medically important pathogenic fungi. As shown in Table 2, all of the topsentins $(\mathbf{1}-\mathbf{4})$ were inactive against fungal cell growth. However, hamacanthins, especially hamacanthin A (5), showed potent antifungal activity against $C$. albicans (MIC: $6.25 \mu \mathrm{g} / \mathrm{ml})$ (determined after $48-\mathrm{h}$ incubation at $28^{\circ} \mathrm{C}$ ). It has also been reported that hamacanthins A (5) and B (7) showed significant antimicrobial activity against $C$. albicans ATCC 44506 and C. neoformans ATCC 32045 with MIC values of $1.6-6.2 \mu \mathrm{g} / \mathrm{ml}$ (determined after $24-\mathrm{h}$ incubation at $\left.37^{\circ} \mathrm{C}\right) .{ }^{8}$ However, we found that hamacanthin B (7) showed weak antimicrobial activity against $C$. albicans, with MIC values of $25-100 \mu \mathrm{g} / \mathrm{ml}$. The difference in MIC values probably reflects differences in incubation conditions and test strains between the two groups. Interestingly, in the present study, the 3,4-dihydrogenation of the pyrazinone ring (compound 6) led to a total loss of activity $(>100 \mu \mathrm{g} / \mathrm{ml})$ against fungal growth. Moreover, compound 5 containing a 3,6-disubstituted pyrazinone ring was more active than 7 containing a 3,5-disubstituted pyrazinone ring. These results also demonstrate that, as shown for antibacterial activity, the presence of the 3,6-disubstituted-5,6-dihydro-1(2H)-pyrazinone skeleton is an important factor for the antifungal activity of the compounds of the hamacanthin class. Currently, however, we cannot fully explain the mode of action of antimicrobial activity of these bis(indole) alkaloids. For bis(indole) alkaloids containing either an imidazole- or pyrazinone-derived spacer unit, only the pharmacologic activity ${ }^{8,10-14)}$ has been investigated so far, and little is known about their molecular mechanism of action.

It was previously reported that bromotopsentin (3) shows cytotoxicity against the $\mathrm{P} 388$ cell line with an $\mathrm{IC}_{50}$ value of $7.0 \mu \mathrm{g} / \mathrm{ml}^{11)}$ Bromodeoxytopsentin (2) was reported to exhibit cytotoxicity against the human leukemia cell line K-562 with an $\mathrm{IC}_{50}$ value of $0.6 \mu \mathrm{g} / \mathrm{ml}$. $^{12)}$ In our determination of the cytotoxicity of topsentins and hamacanthins against selected cancer cell lines using the MTT assay, these compounds exhibited moderate activity against adenocarcinoma (AGS) and lymphocytic leukemia (L1210) (Table 3). However, activities against breast cancer (BC) and hepatoma (HepG2) were considerably weaker and only compounds $\mathbf{1}$, $\mathbf{4}$, and $\mathbf{5}$ displayed moderate activity against these cell lines.

In conclusion, we evaluated the antimicrobial and cytotoxic activities of bis(indole) alkaloids of the topsentin class (1-4) and hamacanthin class (5-9). These compounds exhibited significant antibacterial activity against Gram-positive and Gram-negative bacteria. Hamacanthin class compounds also showed potent antifungal activity, while the topsentin class was inactive. When compared with the structures of isolated bis(indole) alkaloids, the imidazole and piperazinone skeletons proved to be important factors for antimicrobial activity, changing selectivities and MIC values. 
These bis(indole) alkaloid compounds also exhibited moderate cytotoxicity against cancer cell lines.

Acknowledgments This research was supported by a grant (R01-2004-000-10429-0) from the Basic Research Program of the Korea Science and Engineering Foundation. T. H. Lee is the recipient of a fellowship from the Ministry of Education through the Brain Korea 21 Project. J. G. Kim is the recipient of a fellowship from the Korea Research Foundation Grant (KRF-2004-005-F00055).

\section{REFERENCES}

1) Walsh C., Nature Rev. Microbiol., 1, 65-70 (2003).

2) Bae M. A., Yamada K., Uemura D., Seu J. H., Kim Y. H., J. Microbiol. Biotechnol., 8, 455-460 (1998).

3) Cho K. W., Seo Y., Yoon T., Shin J., J. Microbiol. Biotechnol., 9, 709715 (1999).

4) Mayer A. M., Hamann M. T., Mar. Biotechnol., 6, 37-52 (2004).

5) Faulkner D. J., Nat. Prod. Rep., 19, 1—48 (2002).

6) Tsujii S., Rinehart K. L., Gunasekera S. P., Kashman Y., Cross S. S., Lui M. S., Pomponi S. A., Diaz M. C., J. Org. Chem., 53, 5446-5453 (1988).

7) Casapullo A., Bifulco G., Bruno I., Riccio R., J. Nat. Prod., 63, 447-
$451(2000)$.

8) Gunasekera S. P., McCarthy P. J., Kelly-Borges M., J. Nat. Prod., 57, 1437-1441 (1994).

9) Mancini I., Guella G., Pietra F., Debitus C., Waikedre J., Helv. Chim. Acta, 79, 2075-2082 (1996).

10) Morris S. A., Andersen R. J., Tetrahedron, 46, 715-720 (1990).

11) Sakemi S., Sun H. H., J. Org. Chem., 56, 43044307 (1991).

12) Shin J., Seo Y., Cho K. W., Rho J. R., Sim C. J., J. Nat. Prod., 62, 647-649 (1999).

13) Wright A. E., Pomponi S. A., Cross S. S., McCarthy P. J., J. Org. Chem., 57, 4772-4775 (1992).

14) Bao B., Sun Q., Yao X., Hong J., Lee C. O., Sim C. J., Im K. S., Jung J. H., J. Nat. Prod., 68, 711-715 (2005).

15) Phife D. W., Ramos R. A., Feng M., King I., Gunasekera S. P., Wright A., Patel M., Pachter J. A., Coval S. J., Bioorg. Med. Chem. Lett., 6, 2103-2106 (1996).

16) Oh K. B., Mar W., Kim S., Kim J. Y., Oh M. N., Kim J. G., Shin D., Sim C. J., Shin J., Bioorg. Med. Chem. Lett., 15, 4927-4931 (2005).

17) Kim S., Oh K. B., J. Microbiol. Biotechnol., 12, 1006-1009 (2002).

18) National Committee for Clinical Laboratory Standards. Approved standard M27-A2, NCCLS, Villanova, PA, U.S.A., 2002.

19) Shin D. S., Oh M. N., Yang H. C., Oh K. B., J. Microbiol. Biotechnol., 15, 216-220 (2005).

20) Association of Official Analytical Chemists, 16th Edition, AOAC International, Arlington, VA, U.S.A., 1995, pp. 6:1-6:18.

21) Mosmann T., J. Immunol. Methods, 65, 55-63 (1983). 